\title{
EVALUATION OF PREGNANCY OUTCOME IN HEART DISEASE COMPLICATING PREGNANCY
}

\author{
G. Mahalakshmi ${ }^{1}$, P. Nirmala², K. Shravanya ${ }^{3}$
}

${ }^{1}$ Associate Professor, Department of Obstetrics \& Gynaecology, Gandhi Medical College, Musheerabad.

${ }^{2}$ Assistant Professor, Department of Obstetrics \& Gynaecology, Gandhi Medical College, Musheerabad.

${ }^{3}$ Post Graduate Student, Department of Obstetrics \& Gynaecology, Gandhi Medical College, Musheerabad.

\begin{abstract}
OBJECTIVES

To evaluate the maternal and foetal outcome in pregnancies complicated by heart disease.

\section{METHODS}

A retrospective evaluation of 62 pregnant cardiac patients, who were managed in a tertiary care centre over a period of one year (January 2015 to December 2015), regarding the incidence, aetiology of cardiac disease, obstetric and cardiac complications, maternal and foetal outcome.

\section{RESULTS}

The incidence of heart disease in pregnancy in the present study is $0.9 \%$. Rheumatic heart disease (Mitral stenosis) is still the predominant cause (44 cases, $71 \%$ ) of heart disease in pregnancy followed by congenital heart disease (11 cases, 17.7\%). In miscellaneous group, peripartum cardiomyopathy ( 9 cases, $14.5 \%$ ) is the leading cause. Maternal and foetal outcome was poor in NYHA functional class III and IV. Most of the women delivered vaginally (33 cases, 51.6\%), spontaneous in onset and at term gestation. However, 12 cases (37.5\%) delivered prematurely; $30.7 \%$ of cases had cardiac complications during the present study. Maternal mortality was high (11.3\%). There were 7 cases of maternal death. All of these patients were in NYHA class III and IV, unbooked, presenting for the first time and with the complications.
\end{abstract}

\section{CONCLUSION}

The study concludes pregnancy in women with heart disease not only poses a risk of maternal mortality and also morbidity due to heart failure, stroke and cardiac arrhythmias and foetus is also affected with prematurity, Intrauterine Growth Restriction (IUGR) and risk of perinatal mortality.

\section{KEYWORDS}

Rheumatic Heart Disease (RHD), Congenital Heart Disease (CHD), Peripartum Cardiomyopathy, Maternal Mortality.

HOW TO CITE THIS ARTICLE: Mahalakshmi G, Nirmala P, Shravanya K. Evaluation of pregnancy outcome in heart disease complicating pregnancy. J. Evolution Med. Dent. Sci. 2016;5(43):2657-2660, DOI: 10.14260/jemds/2016/622

\section{INTRODUCTION}

The causes of maternal heart disease are diverse and its management is complex. Prevalence of heart disease in pregnancy varies between 0.3 to $3.5 \% .^{1,2}$ Heart disease in pregnancy is one of the common indirect obstetric causes of maternal death. In developing countries like India, rheumatic heart disease still remains prevalent. ${ }^{3}$ whereas in developed countries congenital heart disease accounts for most of the cases in pregnancy. 4

With advances in cardiac surgery and medications, most of the infants and children with congenital and acquired heart disease now survive into their child bearing age. ${ }^{5}$

Peripartum cardiomyopathy is associated with high rate of cardiac complications and maternal death. ${ }^{6}$ Now there is an increase in incidence of ischaemic heart disease with increasing number of pregnancies in older women and in women with risk factors such as obesity, diabetes, smoking, etc.

Financial or Other, Competing Interest: None.

Submission 29-03-2016, Peer Review 22-04-2016,

Acceptance 29-04-2016, Published 27-05-2016.

Corresponding Author:

Dr. G. Mahalakshmi,

H. No: 2-2-647/276

Srinivasnagar Colony,

Bagh Amberpet-500013,

Hyderabad.

E-mail: golimahalakshmi8@gmail.com

DOI: $10.14260 /$ jemds/2016/622
New York Heart Association (NYHA) functional class $\geq$ II at baseline are associated with higher maternal morbidity and mortality.7,8 Cardiac patients with associated anaemia, preeclampsia, diabetes, infections have poorer prognosis. In many women, heart disease is first recognized during their pregnancy due to unmasking by pregnancy associated cardiovascular changes. ${ }^{9}$ Complications resulting in maternal death are cardiac failure, thromboembolism and haemorrhagic episodes. ${ }^{10}$

\section{AIMS AND OBJECTIVES}

The primary objective of the present study is to evaluate the incidence of different cardiac lesions during pregnancy and to assess the effects of heart disease on maternal and foetal outcome.

\section{MATERIALS AND METHODS}

It is a retrospective study conducted in the Department of Obstetrics and Gynaecology, Gandhi Medical College, over a period of one year (January 2015 to December 2015).

It is a tertiary care centre providing services to a large obstetric population covering 4-5 districts. Total number of deliveries during study period were 8072 and 62 pregnant cardiac patients were enrolled. It included pregnant women with known cardiac disease as well as those with heart disease diagnosed for the first time during this pregnancy, both booked and unbooked cases.

The patients were divided into three groups. Rheumatic heart disease, congenital heart disease and miscellaneous. 
They were also subdivided into surgically corrected and uncorrected cases. Baseline data recorded included age, parity, gestational age at presentation, prior cardiac events, cardiac lesions, prior surgical interventions and use of cardiac medications. NYHA functional class was assessed at each visit. Thorough clinical examination including chest auscultation and obstetric examination was done.

They were regularly seen at antenatal clinic, frequency of visits depending on the cardiac status and gestational age in coordination with cardiologist. Advised rest, iron, folic acid, calcium supplements and cardiac medications. Routine investigations, ECG, 2D Echocardiography were done in all cases and diagnosis confirmed. Unbooked cases were managed as per their cardiac condition.

Patients in NYHA class I and II were admitted to hospital at 36 weeks and patients in NYHA class III and IV were admitted throughout their pregnancy and remained for 2 weeks following delivery. Vaginal delivery was the aim, waiting for spontaneous onset of labor. Labor was induced only in a very few cases. Caesarean section was done only in obstetrically indicated cases.

\section{RESULTS}

A total of 62 cases of pregnancy complicated by heart disease were studied. The incidence of heart disease in pregnancy in the present study is $0.9 \%$. Demographics shown in Table I. Most of the cases in the present study were of the age group 21-25 yrs. (38 cases (61\%), primigravidas (25 cases $(40 \%)$ ) and were unbooked cases (40 cases $(64.5 \%)$ ). Heart disease was diagnosed before pregnancy in 37 cases (59.5\%), during this pregnancy in 22 cases (35.5\%) and postpartum period in 3 cases (4.8\%); 52 cases (84\%) were in NYHA functional class I and II.

The predominant cause of heart disease in the present study is rheumatic heart disease (39 cases, 62\%) followed by congenital heart disease (12 cases, $19.4 \%$ ). Mitral stenosis is the most common lesion in RHD group (18 cases, 29\%), atrial septal defect is the commonest lesion in CHD group (6 cases, $9.6 \%$ ) and peripartum cardiomyopathy in miscellaneous group ( 9 cases, $14.5 \%$ ). These findings were in agreement with other Indian studies. ${ }^{11,12}$ The distribution of cases as per the type of lesion is shown in Table III; 12 cases (19.4\%) had surgical corrections before this present pregnancy, out of which 4 cases $(6.4 \%)$ had mitral valve replacement and were on anticoagulant therapy.

The major complications that were encountered during the management of 62 cases are shown in Table V. The predominant complication was acute pulmonary oedema in 5 cases $(8.1 \%)$ and another 14 cases $(22.6 \%)$ suffered with various cardiac complications.

Maternal outcome is shown in Table VI. Majority of the women delivered vaginally 33 cases (53.2\%) with spontaneous onset of labour in 26 cases (42\%), only 3 cases $(4.8 \%)$ required induction of labour due to post-dated pregnancy ( 1 case, $1.6 \%$ ), intrauterine foetal death ( 2 cases, $3.2 \%) ; 24$ women (38.7\%) were delivered by lower segment caesarean section due to various obstetric indications. There was one case of craniotomy for IUFD with cephalopelvic disproportion; 11 cases $(17.7 \%)$ required ventilator support. There were 7 maternal deaths (11.4\%); all of these women were in NYHA class III or IV, unbooked and presented with complications of pulmonary oedema or congestive cardiac failure or thromboembolism. Subbaiah et al reported that pregnancy with NYHA functional class III or IV are associated with high maternal mortality. ${ }^{13}$ Peripartum cardiomyopathy was the most frequent aetiological cause of maternal death $(3$ cases, $42.8 \%$ ) in the present study. ${ }^{14}$ Other studies also found similar results. ${ }^{8}$

Perinatal outcome is shown in Table VII. In the present study, 52 babies $(91.2 \%)$ were born alive, still births were seen in 5 cases (8.8\%). Babies born weighed more than $2.5 \mathrm{~kg}$ in $45.6 \%$ of the cases; $39 \%$ of the babies were growth restricted, preterm deliveries were seen in 12 cases (21\%), NICU admission in 5 cases. Malhotra et al also found high rate of preterm delivery, low birth weight among cardiac patients when compared to non-cardiac patients. ${ }^{15}$

\begin{tabular}{|c|c|c|}
\hline Parameter & Number of Cases & Percentage \% \\
\hline Age in Years & & \\
$<20$ & 38 & 11 \\
$21-25$ & 12 & 61 \\
$26-30$ & 5 & 19.4 \\
$>30$ & & 8.1 \\
\hline Parity & 25 & 40 \\
Primi & 21 & 34 \\
Gravida 2 & 8 & 13 \\
Gravida 3 & 6 & 7 \\
Gravid >=4 & & \\
\hline Hospital & 22 & 35.5 \\
Admission & 40 & 64.5 \\
Booked & & \\
Unbooked & 15 & 24 \\
\hline Time of Diagnosis & 22 & 35.5 \\
Before conception & 22 & 4.8 \\
In previous & 03 & \\
pregnancy & & \\
Antenatal period & Postnatal period & \multicolumn{2}{|c|}{ Table I: Demographic Variables } \\
\hline \multicolumn{2}{|c|}{}
\end{tabular}

\begin{tabular}{|c|c|c|}
\hline Parameter & Number of Cases & Percentage \% \\
\hline NYHA & 36 & 58 \\
Class I & 16 & 26 \\
Class II & 07 & 11.2 \\
Class III & 03 & 4.8 \\
Class IV & Table II: Functional Grading (NYHA Classification) \\
\hline
\end{tabular}

NYHA - New York Heart Association

\begin{tabular}{|c|c|c|c|}
\hline Type of Heart Disease & Cardiac Lesion & Number of Cases & Percentage \% \\
\hline & MS+MR+TR & 18 & 29 \\
Rheumatic Heart Disease & MR+AR & 12 & 19.4 \\
(RHD) & Post MVR & 04 & 6.5 \\
(39 cases 62\%) & AR & 02 & 3.2 \\
& MVP+mild MR & 02 & 3.2 \\
\hline Congenital Heart Disease (CHD) & Moderate AS & 01 & 1.6 \\
\hline
\end{tabular}




\begin{tabular}{|c|c|c|c|}
\hline (12 Cases 19.3\%) & Ventricular septal defect (VSD) & 03 & 4.8 \\
& Aortic stenosis (Biscuspid & 01 & 1.6 \\
& aortic valve) & 02 & 3.2 \\
\hline \multirow{3}{*}{ Miscellaneous } & Ebstein anomaly & 09 & 14.5 \\
& Peripartum cardiomyopathy & 01 & 1.6 \\
& RBB with WPW syndrome & 01 & 1.6 \\
\hline \multicolumn{2}{|c|}{ Table III: Distribution of Cases as Per Type of Lesion }
\end{tabular}

RBB - Right Bundle Branch Block, WPW - Wolff-Parkinson-White Syndrome, LVH - Left Ventricular Hypertrophy

\begin{tabular}{|c|c|c|c|c|}
\hline \multicolumn{3}{|c|}{$\begin{array}{c}\text { Surgically } \\
\text { Corrected Cases } \\
\text { (12 Cases, 19.4\%) }\end{array}$} & \multicolumn{2}{|c|}{$\begin{array}{c}\text { Uncorrected } \\
\text { Cases } \\
\text { (50 Cases, 80.6\%) }\end{array}$} \\
\hline $\begin{array}{l}\text { RHD } \\
\text { MVR } \\
\text { PBMV }\end{array}$ & $\begin{array}{l}04 \\
03\end{array}$ & $\begin{array}{c}33.3 \\
25\end{array}$ & 32 & 64 \\
\hline $\begin{array}{c}\text { CHD } \\
\text { VSD closure } \\
\text { ASD closure }\end{array}$ & $\begin{array}{l}02 \\
03\end{array}$ & $\begin{array}{c}16.6 \\
25\end{array}$ & 07 & 14 \\
\hline Table IV & & aft & $\begin{array}{l}\text { jical } \\
\text { e }\end{array}$ & \\
\hline
\end{tabular}

MVR - Mitral Valve Replacement, PBMV - Percutaneous Balloon Mitral Valvotomy

\begin{tabular}{|c|c|c|}
\hline Complications & $\begin{array}{c}\text { Number } \\
\text { of Cases }\end{array}$ & $\begin{array}{c}\text { Percentage } \\
\text { \% }\end{array}$ \\
\hline Cardiac Complications & & \\
Acute pulmonary oedema & 05 & 8.1 \\
Congestive cardiac failure & 04 & 6.5 \\
Lower respiratory tract & 01 & 1.6 \\
infection & 01 & 1.6 \\
Sustained arrhythmia & & \\
requiring treatment & 02 & 3.2 \\
Thromboembolism & 00 & 0 \\
Bacterial endocarditis & & \\
Associated Obstetric & 06 & 9.7 \\
Complications & 13 & 21 \\
Preeclampsia & 12 & 19.4 \\
Previous caesarean section & 03 & 4.8 \\
Anaemia & 05 & 8.1 \\
Antepartum haemorrhage & 02 & 6.2 \\
Mal presentations & 04 & 12.4 \\
Twins & \\
Post-partum haemorrhage & & \\
\hline Table V: Associated Complications of Heart \\
Disease in Pregnancy
\end{tabular}

\begin{tabular}{|c|c|c|}
\hline & $\begin{array}{c}\text { Number of } \\
\text { Cases }\end{array}$ & $\begin{array}{c}\text { Percentage } \\
\mathbf{\%}\end{array}$ \\
\hline Mode Delivery & 24 & 38.7 \\
LSCS & 33 & 53.2 \\
Vaginal Delivery & 26 & 78.8 \\
SPVD & 03 & 9 \\
Induction of labour & 04 & 12 \\
Instrumental delivery & 01 & 3 \\
Craniotomy for IUFD & 05 & 8.1 \\
\hline Undelivered and & 11 & 17.7 \\
\hline death & 55 & 88.7 \\
\hline On ventilator support & 07 & 11.3 \\
\hline Healthy and & discharged & \multicolumn{2}{|c|}{ Table VI: Maternal Outcome } \\
\hline \multicolumn{2}{|c|}{ Maternal death }
\end{tabular}

LSCS - Lower Segment Caesarean Section, SPVD Spontaneous Vaginal Delivery

\begin{tabular}{|c|c|c|}
\hline Parameter & Number of Cases & Percentage \% \\
\hline Live birth & 52 & 91.2 \\
IUFD & 02 & 3.5 \\
Neonatal death & 03 & 5.2 \\
\hline Weight (Kg) & 04 & 7 \\
$<1.5$ & 16 & 28 \\
$1.6-2$ & 11 & 19.3 \\
$2-2.5$ & 26 & 45.6 \\
$>2.5$ & 43 & 75.4 \\
Term & 12 & 21 \\
Preterm & 05 & 8.8 \\
NICU admission & \multicolumn{2}{|c|}{ Table VII: Foetal Outcome } \\
\hline \multicolumn{2}{|c}{}
\end{tabular}

\section{DISCUSSION}

Our present study provides an assessment of maternal and foetal outcome in women with heart disease in pregnancy. It is estimated that 0.3 to $3.5 \%$ of all pregnancies are complicated by heart disease. It accounts for $15 \%$ of all pregnancy related mortality. ${ }^{16}$ The incidence of heart disease in the present study was $0.9 \%$ and maternal mortality was high $(11.3 \%)$. Ours being a referral centre, the results may not reflect the true incidence of this medical disorder in pregnancy in general population.

Although the incidence of heart disease in pregnancy remained unchanged, the relative contribution of different causes of heart disease varies with study population. Our study shows rheumatic heart disease is three times more common than congenital heart disease, emphasizing the need for prevention and treatment of group A streptococcal infection in childhood.

Cardiac failure is the most frequent cause of maternal mortality. Most of them were in puerperium in the present study. So, we stress the need for early detection and treatment of heart failure throughout the course of pregnancy, labour and puerperium. Most of the women with heart disease in pregnancy went into spontaneous labour and delivered vaginally. Majority of the neonates had either average or less than average birth weight. In the present study, many of these women tolerated labour and puerperium due to team approach by obstetrician, cardiologist and anaesthetist.

No cases of bacterial endocarditis were recorded in this study because of our routine practice of giving prophylactic antibiotics. Even though, the working party of British society for antimicrobial therapy recommends prophylaxis only in high risk cases like prosthetic valves, previous history of infective endocarditis, etc., in our Indian setup, prophylaxis against infective endocarditis should be given to all women with heart disease in pregnancy.

In the present study, four women had mitral valve replacement before pregnancy and were on anticoagulants. One patient with mitral valve replacement died of thromboembolism, her PT and INR were not in therapeutic 
range due to irregular treatment. All of them were managed with unfractionated heparin during first trimester and last four weeks before delivery and with warfarin during the rest of the pregnancy and puerperium. Doses were titrated according to PT and INR to maintain therapeutic range.

\section{CONCLUSION}

In the present study, we stressed on the need for cardiac auscultation as routine in all pregnant women in antenatal clinic. Any clinical suspicion should be confirmed by cardiologist. Similarly, prevention and prompt treatment of streptococcal infections is required to reduce the burden of rheumatic heart disease in the society.

Early detection, prior surgical corrections, preconceptional counseling, avoidance of pregnancy in high risk cases, care and delivery in tertiary centres, multidisciplinary approach can go a long way to improve maternal and foetal outcomes.

\section{REFERENCES}

1. Sugrue D, Blake $S$, MacDonald D. Pregnancy complicated by maternal heart disease at the national hospital, Dublin, Ireland 1969-1978. Am J Obstet Gynaecol 1981;139:1-6.

2. McFaul PB, Dornan JC, Lamki $\mathrm{H}$, et al. Pregnancy complicated by maternal heart disease. A review of 519 women. Br J Obstet Gynaecol 1988;95(9):861-7.

3. Carapetis JR. The current evidence for the burden of group A streptococcal diseases. WHO/FCH/CAF/05-07, WHO Geneva. 2004;1-57.

4. Stangl V, Schad J, Gossing G, et al. Maternal heart disease and pregnancy outcome: a single centre experience. Eur J Heart Fail 2008;10(9):855-60.

5. Perloff JK, Warnes CA. Challenges posed by adults with repaired congenital heart disease. circulation 2005;103:16-36
6. Whitehead SJ, Berg CJ, Chang J. Pregnancy related mortality due to cardiomyopathy: United States, 1991-1997. Obstet gynaecol 2003;102(6):1326-31.

7. Siu SC, Sermer M, Colman JM, et al. Cardiac disease in pregnancy (CARPREG) investigators. Prospective multicenter study of pregnancy outcomes in women with heart disease. Circulation 2001;104(5):515-21.

8. Abdel-Hady ES, El-shamy M, El-Rifai AA, et al. Maternal and perinatal outcome of pregnancies complicated by cardiac diseases. Int J Gynaecol obstet 2005;90(1):21-5.

9. Lim ST. Rheumatic heart diseases in pregnancy. Ann Acad Med Singapore 2002;31(3):340-8.

10. Plesinac S, Pilic I. Course and outcome of pregnancy after the heart surgery. In: Proceedings of the medical conference prague. September 2011.

11. Konar H, Chaudhari S. Pregnancy complicated by maternal heart disease: a review of 281 women. Journal of obstetrics and gynaecology of India 2012;62(3):301-6.

12. Bhatla N, Lali S, Behara G, et al. Cardiac disease in pregnancy. Int J Gynaecol and obstet 2003;82(2):153-9.

13. Subbaiah M, Sharma V, Kumar S, et al. Heart disease in pregnancy: cardiac and obstetric outcomes. Arch Gynaecol obstet 2013;288(1):23-7.

14. Pearson GD, Veille JC, Rahimtoola S, et al. Peripartum cardiomyopathy: national heart, lung and blood institute and office of rare diseases workshop recommendations and review. JAMA 2000;283(9):1183-8.

15. Malhotra M, Sharma JB, Tripat Hi R, et al. Maternal and foetal outcome in valvular heart disease. International Journal of Obstetrics and Gynaecology 2004;84(1):11-6.

16. de Swiet M. Heart disease in pregnancy. In de Swiet M, editor. Medical disorders in obstetric practice. Oxford. Black Well, 1984;483-504. 